\title{
New pyranonaphthoquinones and a phenazine alkaloid isolated from Streptomyces sp. IFM 11307 with TRAIL resistance-overcoming activity
}

\author{
Mohamed S Abdelfattah, Toume Kazufumi and Masami Ishibashi
}

The Journal of Antibiotics (2012) 65, 277; doi:10.1038/ja.2012.25

Correction to: The Journal of Antibiotics (2011) 64, 729-734; doi:10.1038/ja.2011.85; published online 21 September 2011

The authors of the above article noticed following errors in the publication of this paper.

Correct E-mail address for the correspondence author is mish@chiba-u.jp.

In Results and Discussion section, on page 732 on 6th line of the printed issue and PDF version a sentence starting 'Additionally' should read 'Additionally NOE correlations between $\mathrm{H}-4$ ' and $\mathrm{H}-5^{\prime}$ b, and $\mathrm{H}-\mathrm{6}^{\prime}$ and $\mathrm{H}-5^{\prime}$ a suggested the configuration of the upper pyrane ring in griseusin E (1) shown in Figure 3.'

In Figure 3. The correct figure is shown below.

Authors apologize for these mistakes.

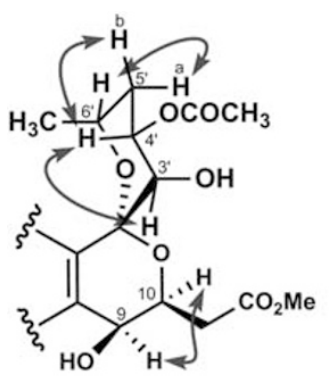

1

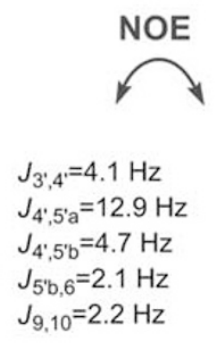

NOE

$9 \mathrm{~Hz}$

$J_{4^{\prime}, 5^{\prime} \mathrm{b}}=4.7 \mathrm{~Hz}$

$J_{9,10}=2.2 \mathrm{~Hz}$

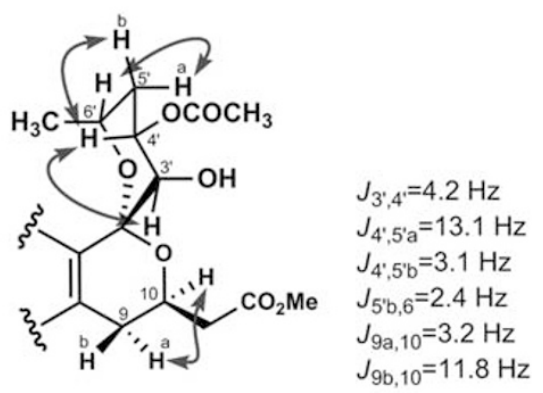

2

Figure 3 Selected NOE correlations and coupling constants of compounds $\mathbf{1}$ and $\mathbf{2}$. A full color version of this figure is available at The Journal of Antibiotics journal online. 